NBER WORKING PAPER SERIES

\title{
BROKEN DOWN BY WORK AND SEX: \\ HOW OUR HEALTH DECLINES
}

\author{
Anne C. Case \\ Angus Deaton \\ Working Paper 9821 \\ http://www.nber.org/papers/w9821
}

\section{NATIONAL BUREAU OF ECONOMIC RESEARCH 1050 Massachusetts Avenue Cambridge, MA 02138 \\ July 2003}

We are grateful to Dan McFadden and to other participants of the NBER Aging Group for comments on an earlier version. This work was funded by a grant from the National Institute on Aging to the NBER. The views expressed herein are those of the authors and not necessarily those of the National Bureau of Economic Research

(C2003 by Anne C.Case and Angus Deaton. All rights reserved. Short sections of text not to exceed two paragraphs, may be quoted without explicit permission provided that full credit including $(\mathbb{C}$ notice, is given to the source. 
Broken Down by Work and Sex: How our Health Declines

Anne C. Case and Angus Deaton

NBER Working Paper No. 9821

July 2003

JEL No. I1

\section{ABSTRACT}

Self-reported health status (SRHS) is an imperfect measure of non-fatal health, but allows examination of how health status varies over the life course. Although women have lower mortality than men, they report worse health status up to age 65. The SRHS of both men and women deteriorates with age. There are strong gradients, so that at age 20 , men in the bottom quartile already report worse health than do men in the top quartile at age 50. In the bottom quartile of income, SRHS declines more rapidly with age, but only until retirement age. These facts motivate a study of the role of work, particularly manual work, in health decline with age. The Grossman capital-stock model of health assumes a technology in which money and time can effect complete health repair. As a result, declines in health status are driven, not by the rate of deterioration of the health stock, but by the rate of increase of the rate of deterioration. We argue that such a technology is implausible, and we show that people in manual occupations have worse SRHS and more rapidly declining SRHS, even with a comprehensive set of controls for income and education. We also find that much of the differences in SRHS across the income distribution is driven by health-related absence from the labor-force, which is a mechanism running from health to income, not the reverse.

\author{
Anne C. Case \\ Department of Economics \\ 345 Wallace Hall \\ Princeton University \\ Princeton, NJ 08544 \\ and NBER \\ accase@princeton.edu
}

\author{
Angus Deaton \\ Department of Economics \\ 347 Wallace Hall \\ Princeton University \\ Princeton, NJ 08544 \\ and NBER \\ deaton@princeton.edu
}




\section{Introduction}

The literature contains many examples of the relationship between health and various measures of socio-economic status, including income, education, and employment. There are undoubtedly multiple causal links between these variables; income and education affect health, and health affects the ability to be educated and the ability to work. There are also third factors that affect both health and socioeconomic status, and that contribute to the correlation between them. Although mortality rates are the gold standard for measuring health status, they are of limited use for investigating the way that health changes over the life-cycle, or the interactions between health, work, earnings and age among the living. Instead, we can use measures of self-reported health status, admittedly imperfect, but certainly informative.

Figure 1 uses data from the National Health Interview Survey to plot self-reported health against age; a higher number means worse health, from 1 through 5, and the graph plots averages of these numbers by age. The age profiles of health for both men and women rise with age although the rate at which health deteriorates with age diminishes sharply after about age 60-65. In spite of their lower mortality rates, women report worse health than men until about age 60-65, after which there is convergence; women also make greater use of physicians' services, at least in the West, though most of this is associated with reproductive health, see Ingrid Waldron (1983) As far as we can tell, this pattern of SRHS by gender is close to universal around the world; it occurs in our own South African data, in India among the elderly, and in many other surveys around the world, see Ritu Sadana, Ajay Tandon et al. (2002)

This picture is substantially different if we stratify by income. Figure 2 shows age profiles for men and women in the top and bottom quartiles of family income. In the top quartile, the fraction 
reporting fair or poor health (which we will refer to here as "poor health") changes little with age until age 45, after which it rises steadily. For the same quartile, and at all ages, men are significantly less likely to report poor health than are women, although the differences are not large at any age (one to two percentage points). In the bottom quartile, self-reported health is quite different. It is much worse than in the top quartile, and it deteriorates more rapidly with age. Indeed, at age 20, men in the bottom quartile already report worse health than do men in the top quartile at age 50. The gender pattern in the bottom quartile is also quite different; women report worse health at young ages, but there is a cross-over around age 50, with women reporting better health thereafter. Health in the bottom income quartile wears out a good deal faster than does health in the top quartile and, at the bottom, men's health deteriorates more rapidly than women's health.

Although there are clearly other factors at work, including mortality selection conditioned on both sex and self-reported health status, these figures suggest that work, especially low-paid or manual work, exacts a price in terms of health, as may the consumption patterns of poorer people, in terms of tobacco use, obesity, lack of exercise, and so on. If low-paid work is harder on health than is high-paid work, people at the bottom of the income distribution will have both lower health and more rapidly deteriorating health, at least while they are working. Women, who over this period had lower labor force participation than men, would suffer less from the ravages of work, and their health would deteriorate less rapidly. It is this suggestion and its implications that we investigate further in this paper. 


\section{A theoretical framework}

As the epidemiological literature illustrates only too sharply, it is extremely difficult to untangle the links between work, earnings, health, and education without some sort of guiding framework. Here we work with a simple intertemporal model of health based on Michael Grossman (1972) whose work is particularly useful in this context because it explicitly analyzes both the level and rate of change of health over the life-cycle, something that, for the purposes of this paper, we take to be directly measured by self-reported health status. We also make use of some of the modifications to Grossman's model introduced by Jana Marja Muurinen (1982). Grossman's analysis has not been widely used for studying the gradient between income and health, perhaps because Grossman himself has emphasized education and not income or wealth, and perhaps because he sees education as making people more efficient at using medical care and other methods of health repair, an interpretation that is antithetical to the explanations favored in the literature on inequalities in health. Even so, Muurinen and Julian Le Grand (1985) have used the Grossman model to interpret the main findings of the Black report, and shown that the model is in fact well-adapted to thinking about these issues.

Muurinen and Le Grand emphasize that people have three kinds of capital, health capital in the form of the health of their bodies, human capital in the form of education, and physical or financial capital in the form of assets. The first of these is more equally distributed across people than the other two; everyone has a body, and most people start life with a healthy body, which deteriorates over time. The rate at which health (body) capital declines with age is partly a biological process over which people have little control, but it is also affected by the extent to which health capital is used in consumption and in work. Manual work is harder on the body than 
non-manual work, and some kinds of consumption activity are harder on the body than others.

Because the three types of capital are to some extent substitutable in generating earnings, as well as in generating utility from a given level of earnings, people who have less human and financial capital have little choice but to rely more heavily on their health capital. In consequence, through an optimal but heavily constrained choice, poorer and less-educated people will experience a more rapid deterioration of health as they age.

A simple model sharpens and modifies these results, and generates explicit predictions about the level and evolution of health over the life-cycle. Suppose that there is an instantaneous felicity function $\mathrm{v}\left(c_{t}, H_{t}\right)$ where $t$ indexes age, $c_{t}$ is consumption, and $H_{t}$ is the stock of health. Health is updated according to

$$
H_{t+1}=\theta m_{t}+\left(1-\delta_{t}\right) H_{t}
$$

where $\boldsymbol{m}_{\boldsymbol{t}}$ is the quantity purchased of medical care or other health promoting activities, $\theta$ is the efficiency with which such purchases create health, and $\delta_{t}$ is the rate at which health deteriorates at age $t$. Equation (1), apparently an innocuous identity, has a number of serious implications to which we return below.

Consumers maximize a life-cycle utility function

$$
U=\sum_{0}^{T}(1+\rho)^{t} v\left(c_{t}, H_{t}\right)
$$

where $\rho$ is the rate of time preference, and $T$ is the length of life, which is potentially a choice variable, though that is an issue that we do not explore here. The life-time present-value budget constraint takes the form 


$$
\sum_{0}^{T} \frac{c_{t}}{(1+r)^{t}}+\sum_{0}^{T} \frac{p_{m} m_{t}}{(1+r)^{t}}=A_{0}+\sum_{0}^{T} \frac{y_{t}\left(H_{t}\right)}{(1+r)^{t}}
$$

where $r$ is the market rate of interest, $p_{m}$ is the price of health-repair goods, $A_{0}$ is initial assets, and $y_{t}\left(H_{t}\right)$ is earnings, which depends on health. For simplicity, we normalize the price of consumption to unity, and assume that the real interest rate and the price of medical care do not vary with age.

The basic equations of the model can most easily be seen by using the health evolution equation (1) to substitute for $\boldsymbol{m}_{\boldsymbol{t}}$ in the budget constraint (3) which gives a single integrated constraint that respects both the financial and the health identities. After minor rearrangement, (1) and (3) yield

$$
\begin{aligned}
\sum_{0}^{T} \frac{c_{t}}{(1+r)^{t}}+ & \sum_{0}^{T} \frac{H_{t}}{(1+r)^{t}} \frac{p_{m}}{\theta}\left(r+\delta_{t}\right)=A_{0}+\sum_{0}^{T} \frac{y_{t}\left(H_{t}\right)}{(1+r)^{t}} \\
& -\frac{p_{m}}{\theta}(1+r)\left[\frac{H_{T+1}}{(1+r)^{T+1}}-H_{0}\right]
\end{aligned}
$$

In this version of the budget constraint, the elements of utility, consumption and health, are multiplied by their respective prices which, in the case of the health stock in period $t$, is the discounted present value of its user cost. As usual, user cost is essentially a carrying charge, which is the sum of interest and physical deterioration, multiplied by the effective replacement price, $p_{m} / \theta$. The right-hand side of (4), which represents the value of lifetime resources, includes the valuation of the health stock after death. In consequence, treating (4) as a standard intertemporal budget constraint implies that the value of the body is like any other asset, which can be accumulated but which can also be sold to finance consumption. The ability to turn one's 
body into cash, or allowing $\boldsymbol{m}_{t}$ to be negative, is clearly not realistic. Even so, the assumption is a convenient starting point, and we shall return later to the (important) consequences of abandoning it and requiring that $m_{t} \geq 0$ so that the rate of decline of health cannot exceed deterioration. As we shall see, it does not change our basic arguments.

From equation (4), the first-order conditions for consumption and health are

$$
\begin{gathered}
\mathrm{v}_{c t}=\lambda\left(\frac{1+\rho}{1+r}\right)^{t} \\
\mathrm{v}_{h t}=\lambda\left(\frac{1+\rho}{1+r}\right)^{t}\left(\frac{p_{m}}{\theta}\left(r+\delta_{t}\right)-y_{h t}\right)
\end{gathered}
$$

where subscripts with respect to $h$ and $c$ denote partial derivatives. The Lagrange multiplier $\lambda$ in (5) and (6) is the shadow price of lifetime wealth, and is constant over the life-cycle. The lifecycle evolution of consumption and health can therefore be conveniently analyzed by examining (5) and (6) with $\lambda$ held constant, a device first used in this context by Adam Wagstaff (1986). Equation (6) permits derivation of the standard comparative static results about the level of health. Provided that there is diminishing marginal utility of health as well as diminishing marginal productivity of health on earnings, the health stock throughout life will be higher (a) the lower is the price of health repair, $p_{m}$, (b) the higher is the efficiency of medical care or other purchases in repairing health, $\theta$, (c) the lower is the rate of health deterioration $\delta_{t}$, (d) the lower is the rate of time preference $\rho$, (e) the higher are initial assets, initial health, or lifetime earnings, and the lower are prices over the lifetime, all of which lower $\lambda$ through lifetime income effects, and (f) the milder is the effect of diminishing returns to health in either consumption or production. 
In Grossman's original model, of which this is a simplified form, the effect of education works to increase the parameter $\theta$, so that health repair is more efficient with the same health inputs, the effective price of health repair is lower, and health is higher throughout the life-cycle. This is true even in the "pure investment" version of the model, in which health has no direct effect on utility, so that $v_{h t}$ is zero, and the health stock is determined through its effects on earnings, by setting the last term on the right-hand side of equation (9) equal to zero. In the pure consumption model, where $y_{h t}$ is zero, or in mixed models with both consumption and earnings effects of health, education will also promote health by lowering $\lambda$ through the lifetime income effects of higher earnings. Muurinen, in her version of Grossman's model, argues that education works so as to reduce the rate of health deterioration, which lowers the user cost of health, and raises its optimal level. Provided that health affects consumption directly, there is also a direct income effect on the health stock through $\lambda$, so that both education and income, conditional on education, should promote health, albeit in different ways. Note finally that the correlation between health and the rate of time preference will also generate a correlation between health and education, if more patient people acquire more education. This is the classic "third factor" explanation of the correlation between health and education proposed by Victor Fuchs (1982).

Our main concern in this paper is the way that health declines over the life-cycle, as well as with how that decline is affected by education, work, and income. The predictions of the theory come from differentiating (5) and (6) with respect to time. We make the assumptions that health and consumption are complementary (or additive) in utility, so that $v_{c h} \geq 0$, and that the instantaneous felicity functions are concave in health and consumption taken together. Then elementary but tedious algebra shows that, when the rate of interest is equal to the rate of time 
preference, health will decline over the life-cycle if and only if the rate of health deterioration $\delta_{t}$ increases with age. If the rate of interest is not equal to the rate of time preference, there is an additional factor which increases the rate of decline of health with age if the rate of time preference exceeds the rate of interest, and which moderates it if the rate of time preference is less than the rate of interest. A lower price of health repair, or a higher efficiency of health repair, through education for example, boosts health throughout the life-cycle, but accelerates its rate of decline if $y_{h t}$ is positive. At retirement, after which there are no earnings and therefore no effect of health on earnings, there will be a discrete increase in the user cost of health—see the righthand side of (6), where $y_{h t}$ reduces the net user cost—which will generate a corresponding drop in health. Subsequent to retirement, the effect of the increasing rate of deterioration on the user cost will be lower because of the absence of the effect of health on earnings, so that the rate of decline of health should be lower immediately after retirement than it was immediately prior to retirement.

When thinking about how health changes with age in this model, it is important to maintain a clear distinction between the rate of health deterioration, which is the quantity $\boldsymbol{\delta}_{t}$, and the rate at which the stock of health changes, $\Delta H_{t}$. The two concepts, which sound very much alike, are quite different, but are linked by the identity (1), which can be written in the form

$$
\frac{\Delta H_{t+1}}{H_{t}}=\frac{\theta m_{t}}{H_{t}}-\delta_{t}
$$

so that expenditure on medical care and other health repair offsets, to a greater or lesser extent, the deterioration in health. There is an important question whether (7), or (1), can be an adequate description of health evolution. In particular, note that (7) implies that the technology allows 
perfect repair of the biological effects of aging, so that it is possible to put a halt to aging, and to postpone death for ever. Grossman's model is different from ours, in that $\boldsymbol{m}_{\boldsymbol{t}}$ is produced using market goods and time, but he assumes constant returns to scale in the technology so that, once again, death can be defeated by sufficiently large amounts of money and time. In a model where time is priced at the market wage, those who can afford to pay for it have the option of eternal life.

Eternal life is more than a than a hypothetical outcome that, while permitted by the technology, will never actually be chosen. If the rate of biological deterioration is constant, which is perhaps implausible but is hardly impossible, (and if the rate of interest is at least as large as the rate of time preference), people will "choose" an infinite life. Otherwise, when the rate of deterioration is increasing with age, people "choose" a finite life, because at some point, the cost of medical care is so high, or the unpleasantness of health repair (exercise?) so extreme, that even death is better. Death is not inevitable, but an optimal choice. That there exists the technology to make this possible would not be claimed by even the most fanatical proponent of the effectiveness of medical care or of the latest programs of exercise and diet.

That the health technology permits complete repair is a problem for health capital models even apart from the possible choice of eternal life. According to (5) and (6), the rate at which health declines over time depends on the rate of increase of $\delta_{t}$, not on its level. Given the identity (7), this implies that medical care or other repair is used fully to offset the level of $\delta_{t}$; indeed if $\delta_{t}$ is constant, the health stock is constant, and repair fully offsets deterioration. But deterioration is proportional to the stock of health, so that these models imply that, controlling for the rate of deterioration $\boldsymbol{\delta}_{t}$ and its rate of change, health repair is higher for healthier people, 
because they have more stock to start with, and deterioration is proportional to the stock. In Grossman's original work, and in several papers since, authors have found a negative correlation between the stock of health and medical care, perhaps not surprisingly given that people tend to seek medical care when they are sick, not when they are well. Of course, these findings may perhaps be attributed to problems with the empirical implementation of the model, Wagstaff (1993), and as Grossman (2000) himself has argued, neither the raw correlation nor the OLS regression of medical care on health can be expected to give the right answer, because of simultaneity through the unobservable components of deterioration, and because health repair involves more than medical care. It is unclear whether there exist feasible methods for correcting these problems and whether an adequate test of the model is possible.

Instead, it is possible that the fundamental problem is not the assumption that people would offset health deterioration if they could, but the assumption that the technology exists that would allow them to do so. If perfect health repair is impossible, we have a very much simpler and more intuitive model of health in which it is the level of physical deterioration that determines the rate of decline of health, with only limited offset possible through behavior. In terms of the optimality conditions (5) and (6), the former will still hold, though the latter will not because, in general, the medical or other technology does not exist to allow the marginal utility of health to be equated to its user cost. One of the issues that we shall examine in our empirical work is whether the rate of health decline in our data is better described by the level or by the rate of change of the rate of physical deterioration in health.

Even within the Grossman model, there is source of health decline even when the rate of physical deterioration is constant. This comes from acknowledging something that we have 
ignored so far, which is that health cannot be sold because purchases of health enhancing goods $m_{t}$ cannot be negative. Suppose that someone is approaching the end of life and in excellent health. According to the basic model (4), good physical health will be traded in for consumption prior to death, but if this is not possible, maintenance will stop, and health will be allowed to decline at the maximum rate possible, which is the rate of health deterioration $\delta_{t}$. Hence, during this period at the end of life, and even within the standard Grossman model, the rate of health decline depends on the level of $\delta_{t}$, not on its rate of change. However, this cannot be the explanation for health declines later in life, because it implies that during this period there would be no purchases of health enhancing goods and $m_{t}=0$. But this is contradicted by the obvious evidence that purchases of healthcare rise with age, not the opposite. And for all periods in which $m_{t}>0$, we are back to the original analysis in which the rate of health decline depends on the rate of change of the rate of deterioration.

A useful extension of the Grossman model, with or without the repair technology, comes from Muurinen and Le Grand's suggestion that people with low education are more likely to work in manual jobs, because non-manual occupations are not open to them. Further, in manual jobs, health deteriorates more rapidly because the nature of the work makes direct demands on physical health through the amount of exertion required, and because many such jobs carry risks of injury (back problems associated with lifting, for example) or other environmental insult. Similarly, people with high wealth or high wages for their level of education will be better able to avoid such jobs. Those who are lucky enough to be born into wealth are rarely observed performing manual work, even when their intelligence and education equip them for little else. We can model such effects explicitly by extending the dependence of earnings on health to 
accommodate an additional choice variable that allows people to enhance their earnings at the expense of faster deterioration in health, effectively selling their health capital. If we write earnings as $y_{t}\left(H_{t}, z\right)$ with a positive partial derivative for $z$, and compensate by writing the rate of deterioration of the health stock as $\delta_{t}(z)$, also with a positive partial derivative, then equations (5) through (6) are unchanged, (or equation (5) is unchanged if (6) does not hold) but we have the additional condition, directly from the budget constraint, that

$$
\frac{\partial y_{t}}{\partial z}=\frac{p_{m}}{\theta} \cdot \frac{\partial \delta_{t}}{\partial z} \cdot H_{t}
$$

so that the marginal addition to earnings from additional manual work is set equal to the marginal health costs, which is the product of the health stock multiplied by the marginal effect on the user cost. The effect of additional manual labor on earnings is lower at higher levels of education, because professors, unlike construction workers, delivery drivers, or professional boxers, get no increase in earnings by wearing out their bodies more rapidly, so that equation (10) implies that physical effort $z$ and health deterioration are higher among those with lower education. If the health stock is optimally adapted to its user cost, the health stock will be higher among the better educated. If not, and the evolution of the health stock is primarily determined by its rate of physical deterioration, then health will decline more rapidly with age among those with less education. Those with education base their earnings on their human capital, which depreciates slowly if at all. Those without education sell their bodies, which depreciate more rapidly.

At a fixed level of education, (8) also implies that those with more health are less likely to undertake heavy labor to improve their earnings because, with more health, they have more to lose from an increase in its rate of depreciation. 
We can also consider a formally identical effect that works through consumption. Suppose that the felicity function contains a second consumption good whose price is paid, not in money, but in the rate of health deterioration. This component includes activities such as smoking, the consumption of junk food, sloth, and cheap risk-taking activities such as unsafe sex, all of which are either low cost or free, all of which are pleasurable, at least to some, but all of which are paid for out of a higher rate of health deterioration. If the second consumption item is $w$, say, the additional first-order condition is

$$
v_{w t}=\lambda\left(\frac{1+\rho}{1+r}\right)^{t} \frac{p_{m}}{\theta} \frac{\partial \delta_{t}}{\partial w} \cdot H_{t}
$$

which, once again holds whether or not health is optimally adapted to its user cost. The difference between (8) and (9) is whether or not health is "sold" directly for utility, or indirectly through the labor market. Holding everything on the right-hand side constant, higher education that changes tastes away from (reduces the marginal utility of) $w$-goods will reduce their consumption, and lower the rate of health deterioration. Of course, education is also likely to increase $\theta$, which will increase the demand for $w$-goods, because it is now easier to repair their damage, and increase lifetime wealth, which increases demand through income effects. As in the production case, higher health status reduces the consumption of $w$-goods, because their effects are proportionately more costly for healthier people.

Note again that equations (8) and (9), with their implication for health deterioration, hold whether or not there is a technology that allows full health repair, although their implications for health and its evolution will differ. If the repair technology is less than perfect then, at least beyond some point, the level of health deterioration will show up as an actual decline in health. 
Manual workers, those with low education, or low wealth, will have higher rates of health deterioration, and their physical health will deteriorate more rapidly with age. With full offset possible, there is no such implication. Unless manual work and unhealthy consumption increase the rate at which health deterioration increases with age, which although possible is far from obvious, they will affect the level of health, but not its rate of decline with age. In our empirical analysis we will examine both the level and rate of change of health across different occupations.

\section{Empirical evidence}

Our data come from the 16 successive waves of the National Health Interview Survey (NHIS) from 1986 through 2001. This is a large nationally representative sample of households, whose members are either interviewed directly, or in the case of children, by proxy. There are 1,209,808 people in the 16 year sample, though for most of the calculations, we work with the subsample of adults aged 18 to 60 , of which there are 711,765 . This provides us with a large enough sample to allow a good deal of disaggregation by age, sex, and occupation. The NHIS is a new crosssection in each year so that, although we can track birth cohorts, for example, we cannot follow any particular individual over time.

The survey collects data on self-reported health status (SRHS) on a scale of 1 to 5 , where 1 is "excellent," 2 is "very good", 3 is "good," 4 is "fair," and 5 is "poor," so that bigger numbers always indicate worse health. There is a very substantial literature on the advantages and disadvantages of this measure of non-fatal health; here we simply accept the measure, and our results are conditioned on that acceptance. In most cases, we respect the ordinal nature of these data by using appropriate techniques, though we will often show averages based on the nominal 1 
through 5 scale.

Family income is collected on a categorical basis, and we assign each person the mid-point of the income range to which they belong and then deflate by the CPI to bring income to 1982 prices. Education is the number of years of education completed. The survey collects information on whether people are in or out of the labor force, and for those who are working, around threequarters of the sample, we have two digit occupational codes. Summary data on education, income, race, and occupation are shown in Table 1. All the means we present, as well as results from subsequent calculations, use the survey weights in order to describe the national population.

The distribution of men and women across occupations is shown down the columns; apart from the omitted category (new workers, military employees, and those whose status is unknown), the occupational columns would sum to one. A little less than 12 percent of the sample is black, and 51 percent are female. The non-manual occupations are listed first, from executives through to administrative support. Apart from the last, where workers are predominantly female, men and women are more or less equally represented in the non-manual occupations. We also show ten manual occupations, where there is a great deal of variation in the fraction of workers who are female.

Our starting point is the information in Figures 1 and 2, presented briefly in the introduction. Figure 1 shows that average health declines with age, is worse for women than for men, but worsens somewhat more slowly with age for women than for men. Figure 2, which shows the same information for people in the top and bottom quartiles of family income, shows that rich and poor people have very different life-cycle patterns of health. The poor have worse health throughout life and their health worsens more rapidly with age. Women "age" (in terms of 
worsening health) less rapidly than do men, but only in the bottom quartile of family income, not in the top quartile. Among the poor, average health stops worsening after age 60. Although there is undoubtedly some role for health- and income-specific mortality in accounting for these results, the patterns of health change by age, by income groups, by sex, and by retirement age, are consistent with the hypothesis that manual work causes health to decline more rapidly than does professional work. As we saw in Section 2, with a technology that allows complete health repair, there is no reason to expect such results, even if there is indeed differential rates of deterioration. Yet the existence of the technology is itself implausible, and Figure 2 might be taken as evidence in that direction.

A more comprehensive investigation requires that we examine occupational effects on health, on which summary evidence is presented in Figure 3. Underlying this figure is an ordered probit for those in work in which SRHS is linked to a set of age, sex, race, and occupational dummies. The Figure shows the estimated coefficients on the occupational dummies. Those to the right (dark bars) are manual occupations, those to the left (lighter bars) non-manual occupations. Consistent with all the theoretical predictions, those employed in manual occupations have worse health than those who work in professional occupations. Police and fire workers are an exception to the general pattern; they are in a manual occupation that carries significant risk of health deterioration, and yet their health status is more like professional than other manual workers. We do not have an explanation for these results, although it is possible that health-based selection into and out of police and fire is sufficiently severe to offset the deterioration associated with the work itself. We can imagine that the same might be true of professional athletes, if we had such data. Selection is important for all of this analysis, and we shall investigate it further below. 
Table 2 takes the results in Figure 3 a step further, disaggregating by sex, and also including controls for income and education. The first column shows the results for men and women combined, while the second and third columns show the results by sex. These again come from ordered probits, now run separately for men and for women. The most notable finding here is how similar the results are for men and women. All non-manual workers are less healthy than executive and administrative workers, with the smallest difference among those in professional and speciality occupations. Male and female manual workers are typically less healthy on average, and the differences by sex are much smaller than differences across occupations. Compared with Figure 3, the inclusion of controls for income and education markedly reduces the estimated occupational effects on health for construction workers and for farmers who are among the least educated and worst paid groups, and who, conditional on education and income, report no worse health than non-manual workers. These effects are essentially the same for men and for women. The clearest exception to the similarity is for men who work in administrative support, an occupation in which there are four times as many women as men. While this case might well be attributed to differential selection, such an argument flies in the face of the evidence from the other occupations where, in spite of substantial differences in the proportions of men and women, their reported health status is very similar. These results provide prima facie evidence for the existence of occupational specific health effects that operate, at least in part, independently of the personal characteristics of the workers. Note also that to the extent that occupational structure contributes to differences in men's and women's health, the effect comes from the allocation of men and women across occupations, not from differences by sex within them. 
Table 2 also shows that there are protective effects of income and education on health even when we control for occupational status. Household income is substantially and significantly more protective for men than for women, a standard result in the literature. Years of education are more protective for women than men, and although the difference is significant given the sample size, it is not very large.

As we saw in Section 2, the existence of level effects in health status across occupations is a less effective test of alternative theories than is the existence of differential rates of change of health. Figure 4 provides evidence on the way that health declines with age during the working life in manual compared with non-manual occupations. Once again, underlying the results is an ordered probit in which SRHS is linked to a complete set of age, sex, and race indicators, and to education, the logarithm of family income, and an indicator for manual occupation. Education and income are interacted with age, and the manual occupation dummy is interacted with a complete set of age dummies. The figure shows the estimated coefficients on these interactions, so that each point shows the difference in health status between manual and non-manual workers at that age. The graph shows a rising pattern from left to right, so that the health difference between manual and non-manual workers is increasing with age. Table 3 shows the relevant results from separate ordered probit equations for males and females. The interaction coefficients are significantly positive for both, but not significantly different from one another. Older nonmanual workers, whether male or female, suffer a greater self-reported health disadvantage than younger non-manual workers. It should be noted that these results are affected by health-specific selection, but because it is the less healthy workers who are selected out—something on which we present evidence below-the increase in the health differential with age is biased downward. 
Selection cannot explain the upward slope that we see in Figure 4.

As we argued in the theoretical section, it is hard to reconcile such effects with a story in which a full repair technology allows people to adjust their health to its user cost. Although manual work causes greater deterioration in the health stock, this is supposed to be offset by repair, so that there is no reason for the health status of manual workers to decline more rapidly with age unless the rate of increase of deterioration with age is itself higher in manual occupations. There is no reason to suppose that this is the case, and indeed, Muurinen and Le Grand (1985) argue that the opposite is likely to be true. They point out that the biological component of health decline is very small among young workers, so that the difference between health deterioration rates of young manual and non-manual workers is almost entirely attributable to differences in their work. Among older workers, by contrast, there is a large common biological component to health deterioration, so that differences due to the work environment generate a smaller proportional difference in overall health deterioration, and thus in the user cost of health. In consequence, the health gradient between manual and non-manual workers should diminish with age, which is exactly the opposite of what we see in Figure 4.

As did Table 2, Table 3 shows that the effects of income and education on health status are not eliminated by controlling for whether people are manual or non-manual workers. Income and education are separately protective, and when we allow for interactions with age, the log of family income has a substantially larger effect for men than for women. Although part of the effect of education works through the selection of occupation, there are other protective effects; according to the theory, there are several ways in which education can reduce the user cost of health. There are also effects of both income and education on the rate at which health declines 
with age. The protective effect of income increases over the working life, while that of education decreases. To account for these, the model with full repair technology would require that the rate of increase of the depreciation rate be lower at high income, and higher at high education. Without full repair, we would require that the levels of deterioration respond in the same way.

That health-based selection is indeed important is documented in Figure 5. This is for men only, and extends beyond the working years and up to age 75. This is a version of Figure 2 for men, but now separating those who are in the labor force from those who are not. The latter have much worse health, presumably because poor health is one of the reasons for being out of the labor force. It is the health of those out of the labor force that worsens rapidly with age until around age 50, and then improves, presumably because more and more people with normal health for their age leave the labor force for normal, non health-related, retirement. Within these two classes, of in and out of the labor force, being at the first versus fourth quartile of income (here taken to be those whose income is within 5 percent of the $25^{\text {th }}$ and $75^{\text {th }}$ percentiles) still affects health in the usual direction, but the effect of income is swamped by the effect of being in or out of the labor force. Figures 2 and 5 are reconciled by noting that the group of those who are out of the labor force and in the top quartile of income is very small. As a result, we conclude that the gradient of health with respect to income in Figure 2 is largely driven by causality running from health to income, through health-related participation in the labor force. As Figure 5 shows, there is still a role for income in conditioning health within each group, and the earlier results of this section show that at least part of this relationship is attributable to the effects of different kinds of work on health, but the major features of Figure 2 can be accounted for by health-based selection in and out of the labor force. 
We turn finally to the issue of health selection at the occupational level, and investigate whether the estimated rate of health decline with age is indeed biased downward by the fact that people who are less healthy drop out of occupations with high rates of wear and tear. Ideally, we would examine this question using panel data that follow people over time. We cannot do this with the NHIS, but we can match birth cohorts in specific occupations over time, and track their size through the successive random population samples in the survey. In particular, we construct occupational birth cohorts by tracking, for example, how many fire and police workers born in 1956 show up in each of the surveys from 1986 through to 2001, and then test whether the number diminishes from one year to the next more rapidly the worse is the average health status of the occupational birth cohort in the first year. Clearly, this technique will only work well if recruitment starts early in the working life, and the profession makes no new hires once its original intake is set. These assumptions are clearly restrictive, but they are the best that we can do given the data available to us.

Table 4 shows the results of the regressions, all of which control for a full set of age, year, and birth cohort dummies. Because of a change in weighting procedures, there is a seam in the series between 1996 and 1997, and this change is omitted from the regressions. The dependent variable is the proportionate change in the number of male workers in the occupation in a given birth cohort. There are 2,210 birth cohort/occupation/year cells for non-manual workers, and 3,981 for manual workers. Columns 1 shows the regression for non-manual workers with different coefficients on health status for each occupation, and Column 2 when the coefficients on health are constrained to be the same across the occupations. All estimated coefficients are positive, and only one is significantly different from zero; collectively the overall effect is 
positive and significant. While it is unclear why cohort size should rise with poor health, there is certainly no evidence that cohort size falls with worse (larger) health status for non-manual workers. For manual workers, in Columns 3 and 4, there is indeed such an effect. Over all the manual occupations, an increase in average health by 0.3 , say, equivalent to the effect of about 20 years of normal aging from 40 to 60 , would be to remove about 3.6 percent of the age-cohort from the workforce. This size of this effect does not vary very much across occupations, but is somewhat higher for machine operators, and considerably lower for firemen and policemen. Health-based selection appears to be real among manual workers, but even those who remain in the occupation grow less healthy with age, and do so at a rate that is larger than that for nonmanual workers, among whom there is no evidence of such health-based selection.

\section{Conclusions}

We started from the observation that self-reported health status worsens with age, and that it does so much more rapidly among those at the bottom of the income distribution, who also start their working lives with lower health. Our original suspicion was that, because manual work involves more wear and tear on the body, the health of manual workers would decline more rapidly than that of non-manual workers, thus offering an explanation for our starting facts. However, the standard health capital model of health, which assumes a technology by which health can be fully repaired, does not predict that health declines more rapidly among those whose work (or consumption) imposes greater demand on their bodies. Instead, people will use medical care or other health repair mechanisms to offset the physical deterioration. Indeed, if the marginal utility of the health stock is set equal to its user cost, as intertemporal optimality requires, the rate of 
health decline is not affected by the rate of wear and tear, but by the rate of increase with age of the rate of wear and tear. Standard arguments suggest that this rate of increase is likely to be lower, not higher, among manual workers. Yet the data from the NHIS show that the health of manual workers does in fact decline more rapidly during the working years than does the health of non-manual workers, in spite of the existence of health-based selection out of manual work which artificially inflates the health of those who remain. We do not find this result at all implausible. Instead, the implausibility lies in the health repair technology that is routinely assumed in the health economics literature.

Although manual workers have worse health than do non-manual workers, and although their health declines more rapidly, the major factor accounting for the differences in health and health decline in different parts of the income distribution is whether or not people are in the labor force, a mechanism where causality runs from health to income, not the reverse. Even so, both income and education have independent protective effects on health for those who are in work, and these effects are reduced but not eliminated by controlling for occupation. With only a few exceptions, we find a marked similarity in all of these results between men and women.

\section{List of works cited:}

Fuchs, Victor R., 1982, "Time preference and health: an exploratory study," in V. R. Fuchs, Economic aspects of health. Chicago, Il. University of Chicago Press for NBER: 93-120. Grossman, Michael, 1972, "On the concept of health capital and the demand for health." Journal of Political Economy, 80: 223-55.

Grossman, Michael, 2000, "The human capital model," in A. J. Culyer and J. P. Newhouse, 
Handbook of Health Economics. Amsterdam, Elsevier. 1A: 347-408.

Muurinen, Jana Marja, 1982, "Demand for health: a generalised Grossman model." J Health Econ, 1(1): 5-28.

Muurinen, Jana Marja and Julian Le Grand, 1985, "The economic analysis of inequalities in health." Social Science and Medicine, 20(10): 1029-35.

Sadana, Ritu, Ajay Tandon, Christopher J. L. Murray, et al., 2002, Describing population health in six domains: comparable results from 66 household surveys. GPE Discussion Paper Series No. 43, Geneva. WHO.

Wagstaff, Adam, 1986, "The demand for health: some new empirical evidence." Journal of Health Economics, 5: 195-233.

Wagstaff, Adam, 1993, "The demand for health: an empirical reformulation of the Grossman model." Health Economics, 2(2): 189-98.

Waldron, Ingrid, 1983, "Sex differences in illness incidence, prognosis and mortality: issues and evidence." Social Science and Medicine, 17(16): 1107-23. 
Table 1. Sample Means, Men and Women Aged 18-60, NHIS 1986-2001

\begin{tabular}{lccc}
\hline \hline & All & Women & Men \\
\cline { 2 - 3 } \cline { 2 - 4 } Age & 37.01 & 37.04 & 36.97 \\
Education & 13.04 & 12.98 & 13.10 \\
Indicator: White & 0.817 & 0.808 & 0.827 \\
Indicator: Black & 0.117 & 0.128 & 0.106 \\
Log(family income) in \$1982 & 9.993 & 9.940 & 10.05 \\
Indicator: Female & 0.510 & 1.000 & 0.000 \\
& & & \\
Occupation: & & & \\
Executive & 0.122 & 0.105 & 0.141 \\
Professional/Specialty Occ & 0.121 & 0.129 & 0.112 \\
Technician & 0.033 & 0.031 & 0.034 \\
Sales & 0.098 & 0.096 & 0.100 \\
Administrative Support & 0.127 & 0.198 & 0.054 \\
Private Household Services & 0.005 & 0.009 & 0.001 \\
Protective Services Fire/Police & 0.015 & 0.005 & 0.025 \\
Service Occ (food, cleaning) & 0.092 & 0.119 & 0.064 \\
Farming/Fishing & 0.021 & 0.007 & 0.036 \\
Mechanic & 0.031 & 0.003 & 0.061 \\
Construction & 0.025 & 0.001 & 0.050 \\
Precision Production & 0.026 & 0.012 & 0.040 \\
Machine Operator & 0.059 & 0.046 & 0.073 \\
Transportation/Moving & 0.037 & 0.007 & 0.067 \\
Handler, Equip Cleaner & 0.033 & 0.013 & 0.053 \\
\hline Out of the labor force & 0.146 & 0.211 & 0.078 \\
& & 374700 & 337065 \\
\hline
\end{tabular}

Occupation columns add to less than one because new workers and military employees are omitted.. All means are weighted, using individual level sample weights provided by the NHIS. 
Table 2. Self-reported health status and occupation Men and Women aged 18-60, NHIS 1986-2001

\begin{tabular}{|c|c|c|c|}
\hline & All & Women & Men \\
\hline Log(household income) & $\begin{array}{l}-.192 \\
(.002)\end{array}$ & $\begin{array}{l}-.179 \\
(.003)\end{array}$ & $\begin{array}{l}-.203 \\
(.003)\end{array}$ \\
\hline Education & $\begin{array}{l}-.067 \\
(.001)\end{array}$ & $\begin{array}{l}-.070 \\
(.001)\end{array}$ & $\begin{array}{l}-.065 \\
(.001)\end{array}$ \\
\hline \multicolumn{4}{|l|}{ Occupation: } \\
\hline Professional/Specialty Occ & $\begin{array}{c}.031 \\
(.006)\end{array}$ & $\begin{array}{c}.056 \\
(.008)\end{array}$ & $\begin{array}{c}.014 \\
(.009)\end{array}$ \\
\hline Technician & $\begin{array}{c}.085 \\
(.009)\end{array}$ & $\begin{array}{c}.089 \\
(.013)\end{array}$ & $\begin{array}{c}.080 \\
(.013)\end{array}$ \\
\hline Sales & $\begin{array}{c}.060 \\
(.006)\end{array}$ & $\begin{array}{c}.089 \\
(.009)\end{array}$ & $\begin{array}{c}.031 \\
(.009)\end{array}$ \\
\hline Administrative Support & $\begin{array}{c}.069 \\
(.006)\end{array}$ & $\begin{array}{c}.062 \\
(.008)\end{array}$ & $\begin{array}{c}.386 \\
(.010)\end{array}$ \\
\hline Private Household Services & $\begin{array}{c}.145 \\
(.022)\end{array}$ & $\begin{array}{c}.165 \\
(.022)\end{array}$ & $\begin{array}{c}.141 \\
(.098)\end{array}$ \\
\hline Protective Services Fire/Police & $\begin{array}{c}.071 \\
(.013)\end{array}$ & $\begin{array}{c}.113 \\
(.028)\end{array}$ & $\begin{array}{c}.066 \\
(.014)\end{array}$ \\
\hline Service Occ (food, cleaning) & $\begin{array}{c}.160 \\
(.007)\end{array}$ & $\begin{array}{c}.171 \\
(.009)\end{array}$ & $\begin{array}{c}.167 \\
(.011)\end{array}$ \\
\hline Farming/Fishing & $\begin{array}{c}.020 \\
(.011)\end{array}$ & $\begin{array}{c}.033 \\
(.024)\end{array}$ & $\begin{array}{c}.019 \\
(.013)\end{array}$ \\
\hline Mechanic & $\begin{array}{c}.155 \\
(.009)\end{array}$ & $\begin{array}{c}.139 \\
(.039)\end{array}$ & $\begin{array}{c}.150 \\
(.010)\end{array}$ \\
\hline Construction & $\begin{array}{c}.074 \\
(.010)\end{array}$ & $\begin{array}{c}.065 \\
(.061)\end{array}$ & $\begin{array}{c}.067 \\
(.011)\end{array}$ \\
\hline Precision Production & $\begin{array}{c}.123 \\
(.010)\end{array}$ & $\begin{array}{c}.179 \\
(.019)\end{array}$ & $\begin{array}{c}.103 \\
(.012)\end{array}$ \\
\hline Machine Operator & $\begin{array}{c}.201 \\
(.008)\end{array}$ & $\begin{array}{c}.253 \\
(.012)\end{array}$ & $\begin{array}{c}.177 \\
(.010)\end{array}$ \\
\hline Transportation/Moving & $\begin{array}{c}.145 \\
(.009)\end{array}$ & $\begin{array}{c}.185 \\
(.024)\end{array}$ & $\begin{array}{c}.140 \\
(.010)\end{array}$ \\
\hline Handler, Equip Cleaner & $\begin{array}{c}.147 \\
(.009)\end{array}$ & $\begin{array}{c}.173 \\
(.019)\end{array}$ & $\begin{array}{c}.159 \\
(.011)\end{array}$ \\
\hline Number of observations & 502374 & 243079 & 259295 \\
\hline
\end{tabular}


Notes on Table 2: Coefficients reported are estimates of the health status expected given this occupation, relative to the omitted category of "executive/administrative." Estimates are based on ordered probits that also include a full set of indicator variables for age, survey year, and indicators that race is white or black. The ordered probit in column 1 also includes an indicator for sex. All ordered probits have been weighted using the individual level sampling weights provided by the NHIS. Standard errors appear in parentheses. 
Table 3. Self-reported health status by manual labor status, Men and Women aged 18-60, NHIS 1986-2001

\begin{tabular}{|c|c|c|}
\hline & Women & Men \\
\hline Manual labor & $\begin{array}{c}.0557 \\
(.0180)\end{array}$ & $\begin{array}{c}.0346 \\
(.0178)\end{array}$ \\
\hline Manual labor×age & $\begin{array}{c}.0017 \\
(.0005)\end{array}$ & $\begin{array}{c}.0013 \\
(.0005)\end{array}$ \\
\hline Log(household income) & $\begin{array}{l}-.0589 \\
(.0093)\end{array}$ & $\begin{array}{l}-.0902 \\
(.0101)\end{array}$ \\
\hline $\log ($ household income $) \times$ age & $\begin{array}{l}-.0036 \\
(.0003)\end{array}$ & $\begin{array}{c}-.0034 \\
(.0003)\end{array}$ \\
\hline Education & $\begin{array}{l}-.0966 \\
(.0038)\end{array}$ & $\begin{array}{l}-.0848 \\
(.0035)\end{array}$ \\
\hline Education $\times$ age & $\begin{array}{c}.0007 \\
(.0001)\end{array}$ & $\begin{array}{c}.0005 \\
(.0001)\end{array}$ \\
\hline Year Indicators? & Yes & Yes \\
\hline Age Indicators? & Yes & Yes \\
\hline Race Indicators? & Yes & Yes \\
\hline Number of observations & 243079 & 259295 \\
\hline
\end{tabular}

Notes: Coefficients reported are estimates of the health status expected given this explanatory variable, relative to White Collar employment at age 18. Estimates are based on ordered probits that also include a full set of indicator variables for age and year, and indicators that race $=$ white and race $=$ black. All ordered probits weighted using individual sampling weights provided by the NHIS. Standard errors appear in parentheses. 
Table 4. Change in labor force participation in given occupations and self-reported health status, reported for men, NHIS 1986-2001

\begin{tabular}{|c|c|c|c|c|}
\hline \multirow[b]{2}{*}{ Health status $\times$ Exec } & \multicolumn{2}{|c|}{ White collar workers } & \multicolumn{2}{|c|}{ Manual workers } \\
\hline & $\begin{array}{c}.051 \\
(.051)\end{array}$ & -- & -- & -- \\
\hline Health status $\times$ Prof & $\begin{array}{c}.065 \\
(.053)\end{array}$ & -- & -- & -- \\
\hline Health status $\times$ Tech & $\begin{array}{l}.117 \\
(.048)\end{array}$ & -- & -- & -- \\
\hline Health status $\times$ Sales & $\begin{array}{c}.055 \\
(.049)\end{array}$ & -- & -- & -- \\
\hline $\begin{array}{l}\text { Health status } \times \text { Admin } \\
\text { support }\end{array}$ & $\begin{array}{l}.070 \\
(.045)\end{array}$ & -- & -- & -- \\
\hline Health status & -- & $\begin{array}{l}.106 \\
(.041)\end{array}$ & -- & $\begin{array}{l}-.122 \\
(.031)\end{array}$ \\
\hline $\begin{array}{l}\text { Health status } \times \text { Protective } \\
\text { (fire, police) }\end{array}$ & -- & -- & $\begin{array}{l}-.082 \\
(.037)\end{array}$ & -- \\
\hline $\begin{array}{l}\text { Health status } \times \text { Service } \\
\text { Occupations }\end{array}$ & -- & -- & $\begin{array}{l}-.099 \\
(.033)\end{array}$ & -- \\
\hline $\begin{array}{l}\text { Health status } \times \\
\text { Farming/Fishing }\end{array}$ & -- & -- & $\begin{array}{l}-.101 \\
(.034)\end{array}$ & -- \\
\hline Health status $\times$ Mechanic & -- & -- & $\begin{array}{l}-.131 \\
(.035)\end{array}$ & --- \\
\hline $\begin{array}{l}\text { Health status } \times \\
\text { Constrction }\end{array}$ & -- & -- & $\begin{array}{l}-.079 \\
(.036)\end{array}$ & -- \\
\hline $\begin{array}{l}\text { Health status } \times \\
\text { Precision Production }\end{array}$ & -- & -- & $\begin{array}{l}-.104 \\
(.036)\end{array}$ & -- \\
\hline $\begin{array}{l}\text { Health status } \times \\
\text { Machine Operators }\end{array}$ & -- & -- & $\begin{array}{l}-.135 \\
(.034)\end{array}$ & -- \\
\hline $\begin{array}{l}\text { Health status } \times \\
\text { Transportation, Moving }\end{array}$ & -- & -- & $\begin{array}{l}-.123 \\
(.034)\end{array}$ & -- \\
\hline $\begin{array}{l}\text { Health status } \times \\
\text { Handlers, Equipment Op }\end{array}$ & -- & -- & $\begin{array}{l}-.099 \\
(.032)\end{array}$ & -- \\
\hline Number of observations & 2210 & 2210 & 3981 & 3981 \\
\hline
\end{tabular}

Notes on Table 4: All regressions include year indicators, age indicators, and birth cohort indicators. 
Figure 1. Self-reported health status by age and sex

NHIS 1986-01

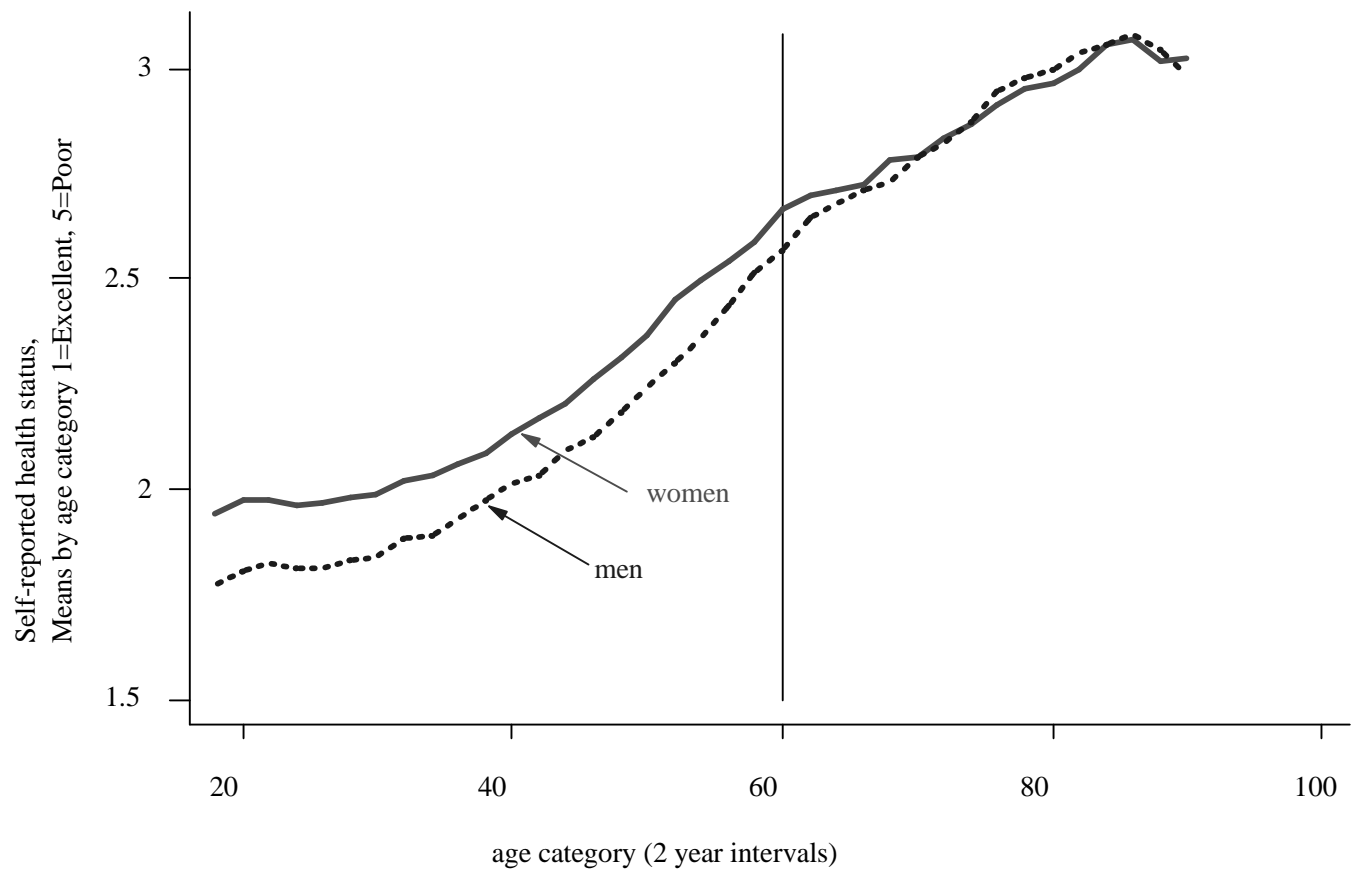


Figure 2. Self-reported health status by age, sex and income quartile,

\section{NHIS 1986-01}

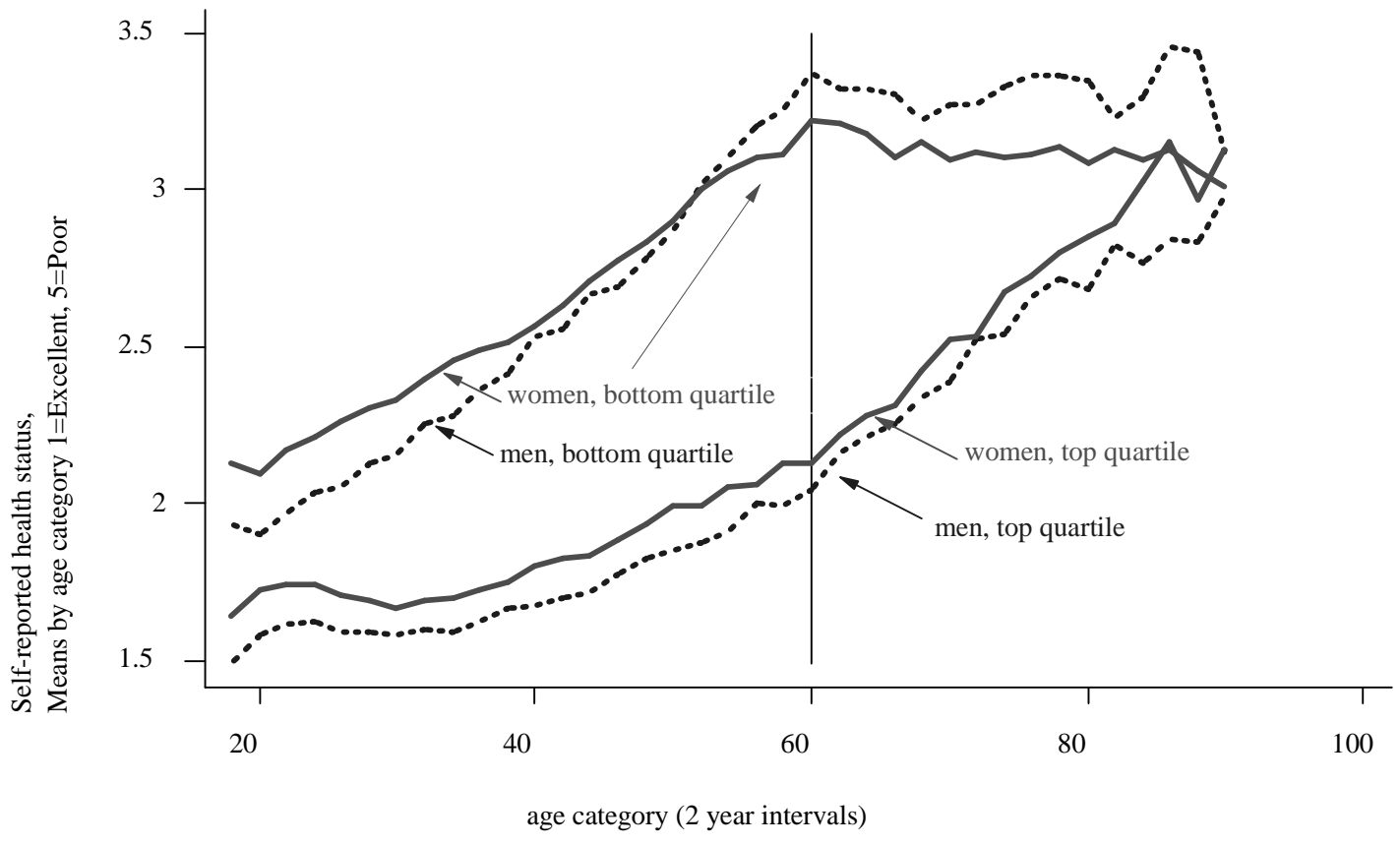


Figure 3. Self reported health status by occupation

NHIS 1986-2001

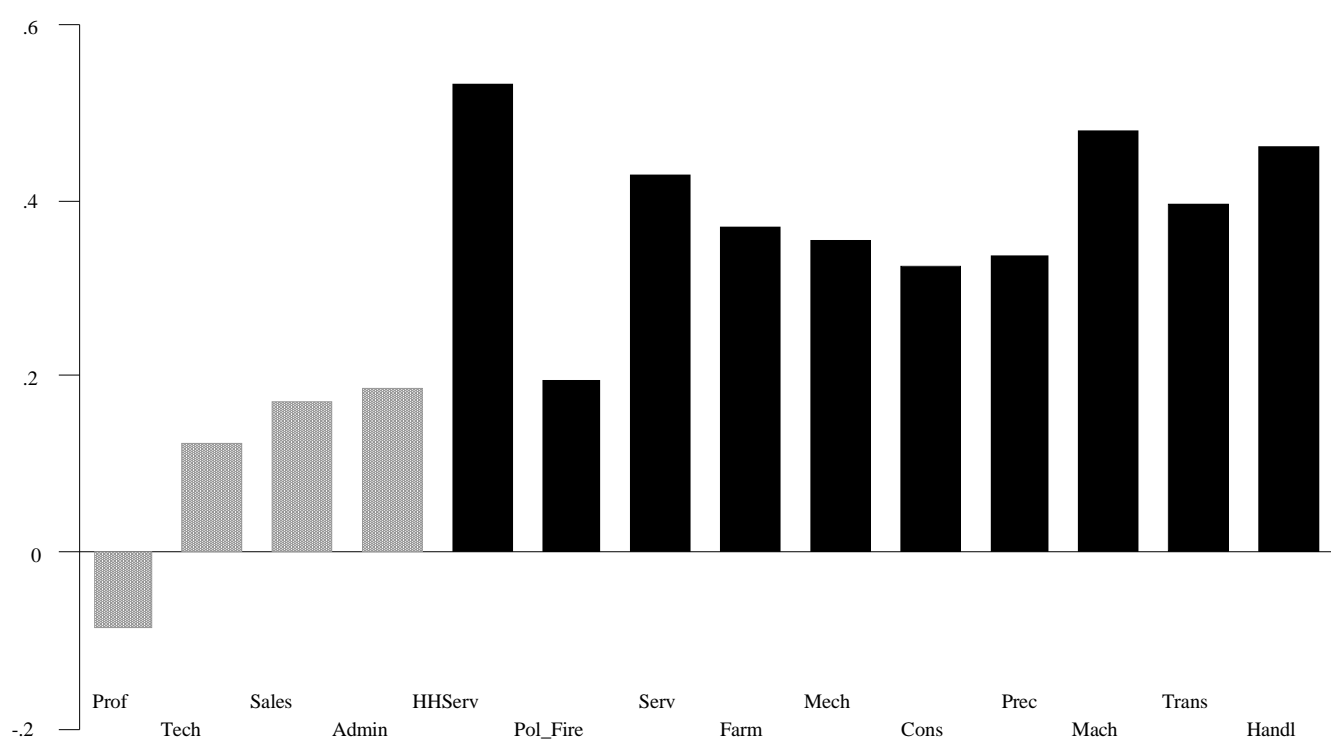

Coefficients on occupation from an ordered probit that includes controls for age, sex and race. Omitted occupation $=$ executive. 
Figure 4. Self-reported health status ordered probit results, Manual labor - age indicator interactions

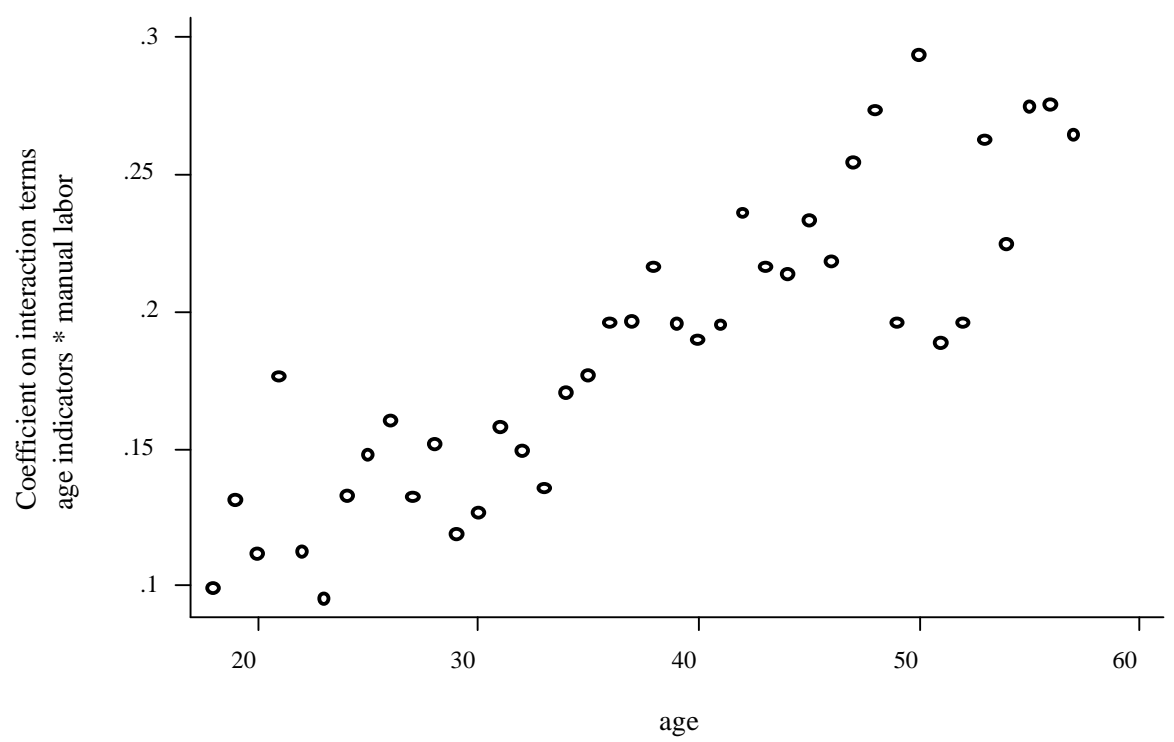

Ordered probit estimation included a complete set of age indicators, education and education interacted with age, $\log$ (family income) and $\log$ (family income) interacted with age, and controls for sex, race and manual labor NHIS 1986-2001 
Figure 5. Self-reported health status by age at the 25th and 75th percentile of the income distribution

By Labor Force Status Men NHIS 1986-01

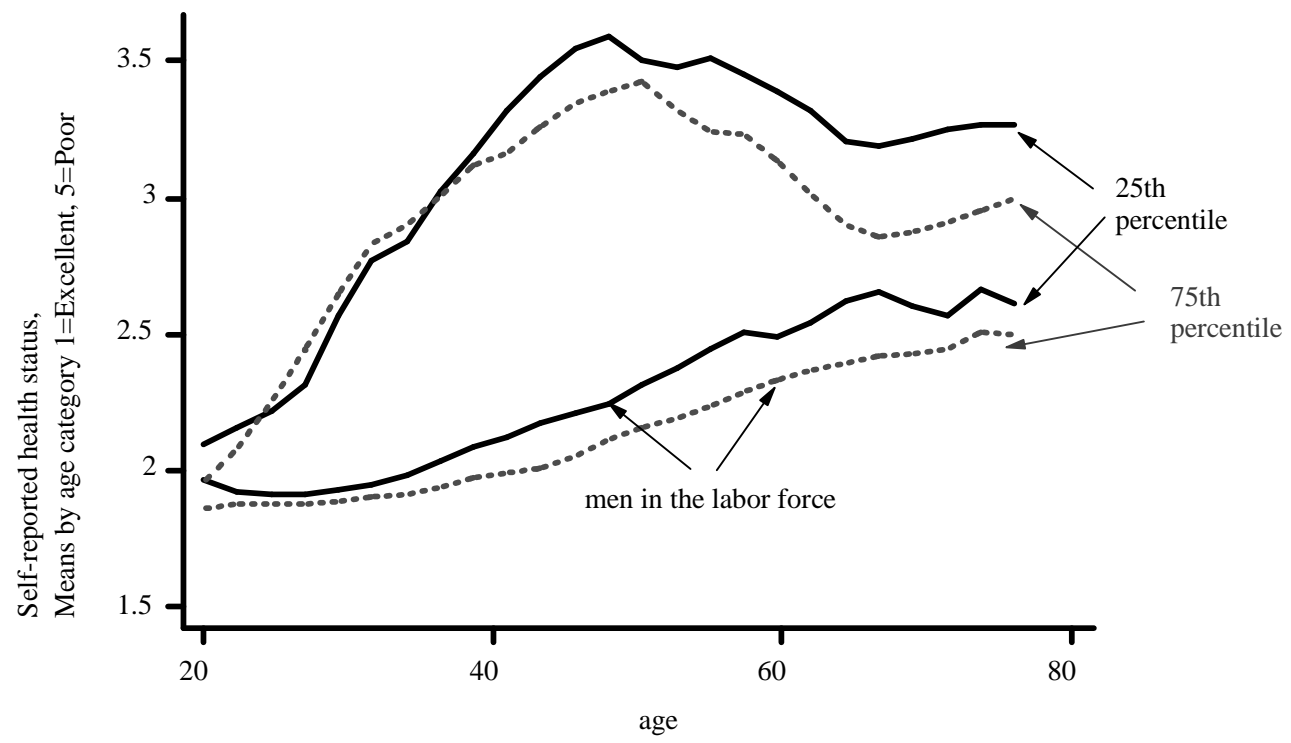

